\title{
A noção de "comportamento" na Filosofia de Merleau-Ponty ${ }^{l}$
}

\author{
Reinaldo Furlan \\ Universidade de São Paulo
}

\begin{abstract}
Resumo
O objetivo deste trabalho é apresentar a noção de comportamento baseado na obra "A Estrutura do Comportamento", de Merleau-Ponty. A noção de estrutura desempenha um duplo papel nesta obra: permite compreender a integração e as rupturas entre as diferentes ordens de fenômenos (físico, vital e humano), bem como apreender a consciência em situação, como emergência de sentido anterior à consciência de si e do mundo. Destaca-se a passagem da ordem vital para a ordem simbólica ou humana e a crítica de Merleau-Ponty a Bergson, que teria biologizado o fenômeno da cultura humana.
\end{abstract}

Palavras-chave: Merleau-Ponty, Fenomenologia, Comportamento, Estrutura.
Key words: Merleau-Ponty, Fenomenology, Behavior, Structure.

\begin{abstract}
The notion of "behavior" in the philosophy of Merleau-Ponty The objetive of the present work is to present the notion of behavior with basis on Merleau-Ponty's of "The Structure of Behavior". The notion of structure plays a double role in that work: it allows understanding both the integration and the ruptures between the different order of phenomena (physical, vital and human), as well as apprehending conscience in situation, as the emergence of a sense anterior to the conscience of self and of the world. The passage from vital order to symbolic or human order, and Merleau-Ponty's criticism to Bergson, who would have biologized the phenomenon of human culture, are highlighted.
\end{abstract}




\section{Introdução}

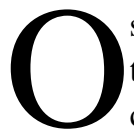
s dois primeiros capítulos d'"A Estrutura do Comportamento" tratam da análise do comportamento reflexo e têm Pavlov como alvo. Através da Psicologia da Forma (Gestalt Psycologie), Merleau-Ponty critica a concepção de relações lineares e pontuais entre os elementos do mundo físico e a fisiologia do organismo, procurando mostrar que o organismo responde aos estímulos e se projeta no meio enquanto unidade vital, isto é, enquanto totalidade ou estrutura. Mais especificamente, a estrutura não se reduz à soma das partes, mas o significado de cada parte depende da estrutura de que participa.

Com esta noção, Merleau-Ponty também prepara a idéia de rupturas entre diferentes ordens de fenômenos, pois se a estrutura representa a formação de um sentido que não pode ser reduzido à soma de suas partes mais elementares, pode-se conceber a passagem de uma estrutura a outra do fenômeno sem pressupor sua redução ao fenômeno mais elementar, no caso, a redução da ordem simbólica ou humana à ordem vital (fisiologia), e a redução desta à ordem do mundo físico. Daí a crítica ao isomorfismo da Gestalt, pois esta não ultrapassa o mundo da física com a noção de estrutura, desembocando no que Merleau-Ponty chama de objetivismo da forma ou da estrutura.

Trata-se, então, de preservar a especificidade do fenômeno da consciência ou percepção humana, que representa a inauguração de uma nova forma de fenômeno, ao mesmo tempo integrando e apoiando-se sobre as ordens física e vital. Mas, tudo isso, sem passar para o lado do idealismo ou do intelectualismo, que acabam apoiando nos atos da consciência toda significação de mundo. No caso, trata-se de apreender a consciência em situação, e esta seria a vantagem da noção de estrutura para Merleau-Ponty, pois a consciência enquanto estrutura é emergência de sentido anterior à consciência de si e do mundo e depende do arranjo contingente dos "elementos" presentes na percepção.

O objetivo deste trabalho é apresentar a passagem da ordem vital para a ordem humana, e mostrar que, enquanto o "animal se organiza um meio estável correspondente aos a priori monótonos da neces- 
sidade e do instinto" - o que marca a ruptura com o sentido do fenômeno físico -, o trabalho humano representa uma nova ordem de fenômeno que projeta no sentido da situação objetos de uso "que constituem o meio próprio do homem e fazem emergir novos ciclos de comportamento" (Merleau-Ponty, 1942/1972, p. 175). O que inaugura, por sua vez, a possibilidade da História ou o ultrapassagem das estruturas assumidas.

\section{A ordem vital e a ordem humana}

Para analisar essa passagem, nos reportamos às famosas experiências de Köehler com primatas, de que Merleau-Ponty se serve para avaliar o sentido do uso que estes fazem de objetos dispostos em seu meio para a consecução de determinados fins.

As mesmas experiências também servem para ilustrar o caráter do rompimento do sentido do comportamento animal com o sentido da ordem física, pois a simples presença física do objeto em seu campo perceptivo não desencadeia automaticamente a ação adequada para a consecução do fim. Mesmo quando em sua presença, é preciso que o chimpanzé integre o objeto ao seu fim, que ele faça, por exemplo, da presença de um "caixote para sentar", um “caixote apoio para alcançar a banana no alto da jaula". Ou seja, os estímulos não podem ser tratados apenas do ponto de vista físico porque são investidos de um valor expressivo para o animal; é seu sentido que conta para ele.

Ora, essas experiências revelam que "o valor instrumental de um objeto decresce na medida em que ele está mais afastado do fim" (Merleau-Ponty, 1942/1972, p.124). Ou seja, na medida em que aumenta a distância espácio-temporal entre o objeto "meio" e o objeto "fim", diminui a possibilidade de seu uso. $\mathrm{O}$ animal não vai à procura de seu instrumento, nem o fabrica, como o homem o fará: se o objeto "meio" não se coloca em seu campo de ação, não é introduzido no circuito entre o desejo do chimpanzé e o objeto a que ele se destina. Ou ainda, "mesmo quando o chimpanzé consegue estender seu campo de ação no tempo como no espaço, e quando ele vai na direção de um alvo final passando por vários intermediários, acontece freqüentemente que o alvo principal, muito próximo, atrai a si as operações que se 
endereçavam ao alvo secundário, e esse fenômeno de 'curto-circuito' mostra que o chimpanzé... está sempre exposto à solicitação do futuro próximo ou da proximidade espacial, que vêm contrair ou deslocar a estrutura da ação" (p. 124-125).

Por isso, podemos falar em um estreitamento do espaço e do tempo vividos pelo animal, em comparação com esses vividos pelo homem, ou de que o homem dispõe do espaço e do tempo de uma forma que vai além das forças imediatas e atuais que compõem o sentido vivido pelo animal.

Merleau-Ponty (1942/1972) procura numa analogia com casos de agnosia e de fadiga do comportamento humano o sentido desse estreitamento:

(É) mais fácil percorrer um itinerário complicado do que explicá-lo a alguém, e freqüentemente, no decorrer da explicação, nós nos servimos de uma mímica motora sem a qual, sobretudo se estamos fatigados, não saberíamos percorrer mentalmente o trajeto... Esse pretenso recurso aos dados táteis é na realidade um recurso ao espaço vivido, em oposição ao espaço virtual no qual nossas indicações se situavam primeiro. Pelos gestos que esboçamos nós fazemos momentaneamente coincidir as direções principais do campo virtual onde se desenrolava nossa descrição com as estruturas fortes - direita e esquerda, alto e baixo - de nosso corpo próprio. A dificuldade de uma descrição pura do itinerário é da mesma ordem que aquela de ler um mapa ou de se orientar sobre um plano, e justamente sabemos que o plano é quase inutilizável em certos casos de agnosia. O traçado puramente visual exige que nós nos representemos o itinerário como visto de cima, de um ponto de vista que nunca foi o nosso quando o percorremos, que sejamos capazes de transcrever uma melodia cinética em diagrama visual, de estabelecer entre um e outro relações de correspondência recíproca e de expressão mútua (p. 127-128).

Uma distinção, pois, entre espaço vivido e espaço virtual, que a "Fenomenologia da Percepção" retoma como a distinção entre movimentos concretos e movimentos abstratos: movimentos concretos limitam-se ao espaço perceptivo atual e representam o comportamento vital propriamente dito - um doente incapaz de tocar com o dedo parte de seu corpo a pedido do médico, toca-a imediatamente após a 
picada de um inseto; movimentos abstratos pressupõem a presença de um espaço virtual que não esse das relações vitais entre meu corpo e o meio - se posso tocar uma parte do corpo a pedido do médico, é porque posso falar do próprio espaço em que me encontro, tomá-lo como objeto ou tema de minhas ações, e é essa função que será afetada em Schneider, cuja análise Merleau-Ponty desenvolve na "Fenomenologia da Percepção": a sua incapacidade de movimento abstrato representa também um estreitamento do espaço e tempo vividos por ele, em última instância, a impossibilidade de um projeto futuro.

Outro modo de abordar a questão é através da análise do comportamento simbólico. É importante notar como Merleau-Ponty une as faculdades kantianas da sensibilidade e do entendimento no sentido do fenômeno da percepção, em que se encontra inscrita a dimensão simbólica do comportamento humano. A vivência espácio-temporal (ou a presença do homem no mundo) e a dimensão simbólica do comportamento fazem parte de uma única experiência de mundo.

No caso em questão, "a cada momento, o animal não pode adotar em relação aos objetos um ponto de vista escolhido livremente, mas o objeto aparece revestido de um 'vetor', investido de um 'valor funcional' que depende da composição efetiva do campo” (Merleau-Ponty, 1942/1972, p. 127). Ou seja, há uma ligação estreita entre o desejo do animal e a disposição dos objetos presentes em seu campo perceptivo, o que torna possível, mesmo, falar em causalidade circular.

Ora, pergunta Merleau-Ponty (1942/1972, p. 127), “o que é que impede as estruturas exteroceptivas de adquirir a mesma plasticidade que encontramos nas estruturas proprioceptivas?". Por que, afinal, o animal entra, sem perder sua unidade corporal, em uma multiplicidade de relações, mas o inverso não ocorre, pois os objetos possuem, para ele, um único significado a cada momento do campo efetivo em que ele se encontra (é curioso notar, nesse sentido, que se um outro chimpanzé senta no caixote, ele imediatamente perde, para aquele que vai usá-lo para alcançar a banana, a função de apoio).

Se o animal não pode variar os pontos de vista sobre o objeto sem perder a sua unidade, isto é, se o objeto assume, a cada vez, um único significado em seu campo perceptivo, é porque "no comportamento 
animal, o objeto exterior não é uma coisa no sentido em que o corpo próprio o é - quer dizer, uma unidade concreta capaz de entrar sem se perder em uma multiplicidade de relações" (Merleau-Ponty, 1942/1972, p. 128). Na falta dessa unidade concreta da ordem do vivido, alguma nova função deve ser acrescentada à percepção da coisa exterior para que ela não se perca durante a experiência, e esta função é a função simbólica. Ou seja,

o que faz falta no animal, é o comportamento simbólico que lhe seria necessário para encontrar no objeto exterior, sob a diversidade de seus aspectos, um invariante comparável ao invariante imediatamente dado do corpo próprio, e para tratar reciprocamente seu próprio corpo como um objeto entre os objetos (p. 128).

Por isso, no comportamento animal, os signos permanecem sempre sinais e nunca tornam-se símbolos; são da ordem do acontecimento - presságios ou "excitantes condicionados" - e não o tema que procura exprimir uma atividade.

\section{A especificidade da percepção humana}

Recusado o intelectualismo ou o movimento da Filosofia Reflexiva (Descartes e Kant) de retorno a uma sede de subjetividade pura ou transcendental como fonte de toda significação (conforme indicado em nossa introdução), Merleau-Ponty passa a analisar outro risco a ser evitado na análise da passagem da ordem vital para o ordem simbólica ou humana. O risco a se evitar, agora, é a descaracterização da especificidade da ordem da cultura humana com sua redução à biologia. Bergson é o alvo privilegiado, pois

no ato do trabalho humano, na construção inteligente de instrumentos, ele só vê uma outra maneira de alcançar os fins que o instinto persegue por sua vez. Há aqui e lá 'duas soluções igualmente elegantes do mesmo problema'. Além da ação biológica, resta apenas uma ação mística que não visa a nenhum objeto determinado. Os atos propriamente humanos - o ato da fala, do trabalho, o ato de se vestir, por exemplo, - não têm significação própria. Eles se compreendem por referência às intenções da vida: a vestimenta é uma pelagem artificial, o instrumento substitui um órgão, a linguagem é um meio de adaptação ao ‘sólido inorganizado' (Merleau-Ponty, 1942/1972, p.176). 
A perspectiva fenomenológica de Merleau-Ponty é notória, nesse momento: a idéia de que o trabalho humano persegue os mesmos fins que o instinto animal pressupõe uma idéia de natureza a que o ser vivo deve se adaptar, o que nos remete, por sua vez, à questão de "como se constituem para nós os objetos da natureza", e "se de fato é a objetos desse gênero que a ação e a percepção humanas se endereçam primeiro" (Merleau-Ponty, 1942/1972, p.178). (Bergson é uma referência importante no pensamento de Merleau-Ponty. Em primeiro lugar, sua filosofia representou um movimento importante no sentido de encarnação da consciência, embora não suficiente, segundo Merleau-Ponty. A despeito de todas as críticas, Merleau-Ponty (1968) reconhece em curso no Collège de France - que a filosofia bergsoniana se dirigia para o que ele chamava então de ontologia do Ser bruto, que ocupava seu pensamento nos anos finais de sua vida).

Ora, com a Psicologia da criança aprendemos que

a percepção iniciante tem o duplo caráter de visar as intenções humanas antes que os objetos da natureza ou que as qualidades puras (calor, frio, branco, negro) das quais elas são portadoras - e de apreendêlas como realidades experimentadas antes que como objetos verdadeiros (Merleau-Ponty, 1942/1972, p.180).

Ou seja, "que a percepção infantil se liga primeiro aos rostos e aos gestos, em particular esses da mãe" (p. 180), e que

resulta disso que é possível perceber um sorriso ou mesmo nesse sorriso um sentimento sem que as cores ou as linhas que o 'compõem', como se diz, o rosto, estejam presentes à consciência ou dados em um inconsciente. Seria preciso, pois, tomar ao pé da letra o fato freqüentemente notado que podemos conhecer perfeitamente uma fisionomia sem saber a cor dos olhos ou do cabelo, a forma da boca ou do rosto. Esses pretensos elementos só estão presentes pela contribuição que eles trazem à fisionomia e é a partir dela que eles são na lembrança penosamente reconstituídos (p.180-181).

Em síntese,

a significação humana é dada antes dos pretensos sinais sensíveis. Um rosto é um centro de expressão humana, o invólucro transparente das 
atitudes e dos desejos de outrém... disso vem, acrescenta MerleauPonty, que nos parece impossível tratar como uma coisa um rosto ou um corpo mesmo morto. São entidades sagradas, não 'dados da vista'... Após o corpo humano, completa, são os objetos de uso criados pelo homem que compõem o campo da percepção iniciante. E com efeito, sua preponderância é marcante com o adulto (p. 181).

Se a percepção iniciante visa antes as intenções humanas do que os objetos da natureza, se a presença de um mundo para a criança se faz primeiro através das intenções do outro que a cercam, é através desse outro e do uso que ele faz de determinados objetos que a criança se introduz no mundo. E aqui, nos damos conta da importância de um objeto de uso, em particular, na constituição do sentido do mundo percebido: trata-se da linguagem convencional. Diz Merleau-Ponty (1942/1972):

Tudo o que nós sabemos da percepção infantil e de suas lacunas, permite pensar que o sentido de uma palavra não se determina no espírito da criança pela comparação dos objetos que ela designa alternadamente, mas pelo recorte dos contextos lógicos dos quais ela faz sucessivamente parte. Não é porque dois objetos se parecem que eles são designados pela mesma palavra, mas ao contrário, porque eles são designados pela mesma palavra e participam assim de uma mesma categoria verbal e afetiva, que eles são percebidos como semelhantes (p. 182).

Uma afirmação que não podemos ignorar na discussão da relação entre o significado da linguagem e o sentido originário da percepção, discussão difícil para Merleau-Ponty e a Fenomenologia de modo geral que, por princípio, procuram no percebido os esboços ou as motivações de sentido que a linguagem assume para levar além com sua expressão. Esta passagem parece, mesmo, constituir certo desequilíbrio em sua obra, a considerar toda sua ênfase na presença de um logos estético ou de um sentido perceptivo que não é da ordem da espontaneidade ou da atividade do pensamento. Talvez o melhor exemplo, nesse sentido, seja a noção de "signo natural", desenvolvida sobretudo na "Fenomenologia da Percepção" (Merleau-Ponty, 1945/ 1994), que significa que a percepção dos perfis das coisas revelam-se 
como uma "linguagem natural" cuja síntese constitui a concretude do sentido da coisa para mim. De qualquer forma, esse sentido lacunar não representa um conjunto de sensações a que a intencionalidade da consciência conferia significado - Husserl -, o que retiraria do percebido qualquer significado próprio.

Também chama a atenção, aqui, o caráter pragmático atribuído à linguagem, cujo sentido se estabelece originariamente ligado a práticas e comportamentos determinados; assim, não se pode desvincular o sentido da linguagem do sentido do meio percebido e da ação de que ela faz parte (contexto lógico) e que ela mesma ajuda a constituir.

Mas, enfim, poderiam retorquir os adeptos das teorias aqui criticadas, esses fatos não colocam nenhum problema especial:

Que a percepção seja primeiro uma percepção das ações humanas ou dos objetos de uso, isso se explicaria simplesmente pela presença efetiva de homens e de objetos de uso no círculo da criança. Que ela só chegue aos objetos através das palavras, isso seria o efeito da linguagem como fenômeno social. Que ela transporte os quadros sociais no próprio conhecimento da natureza, isso só seria uma prova a mais em favor de uma sociologia do conhecimento. Que ela se abra enfim sobre uma realidade que solicita nossa ação antes que sobre uma verdade, objeto de conhecimento, isso resultaria da ressonância na consciência de seu acompanhamento motor. Em outros termos, nós teríamos colocado em evidência os determinantes sociais e fisiológicos da percepção, nós teríamos descrito, não uma forma original de consciência, mas os conteúdos empíricos, sociais ou cinestésicos, que lhe são impostos pela existência do corpo ou pela inserção em uma sociedade e não nos obrigam a modificar a idéia que nós nos fazemos de sua estrutura própria (Merleau-Ponty, 1942/1972, p. 183).

\section{Prossegue Merleau-Ponty (1942/1972):}

Mas nós nos propomos mostrar que o aspecto descritivo da percepção iniciante exige uma reformulação da noção de consciência. A simples presença de fato, no círculo infantil, de outros seres humanos e de objetos de uso ou de objetos culturais não pode explicar as formas da percepção primitiva como uma causa explica seu efeito. A consciência não é comparável a uma matéria plástica que receberia do exterior suas estruturas privilegiadas pela ação de uma causalidade sociológica ou fisiológica. Se essas estruturas não estivessem de alguma maneira pré- 
figuradas na consciência da criança, o objeto de uso ou o 'outro' apenas se exprimiriam nela através dos edifícios de sensações dos quais uma interpretação progressiva deveria destacar tardiamente o sentido humano. Se a linguagem não reencontrasse na criança que escuta falar, alguma predisposição ao ato da fala, ela permaneceria um longo tempo para ela um fenômeno sonoro entre outros (p.183-184).

Não se trata, aqui,

de sustentar a tese absurda de um inatismo das estruturas de condutas fundamentais. Além de que o inatismo concorda mal com os fatos - a influência do meio sobre a formação do espírito é bastante visível, e é claro que uma criança que nunca tivesse visto uma vestimenta não poderia ter a conduta da vestimenta nem falar ou se representar outros homens se ela fosse absolutamente só - ele passa ao lado da dificuldade: ele se limita a transferir 'para' a consciência, isto é, em resumo, para uma experiência interna, os conteúdos que o empirismo deriva da experiência externa (p.184).

Trata-se, portanto, de apreender o momento em que o sentido iniciante se dá, de reafirmar, como dissemos, o caráter originário do sentido da percepção que se faz segundo as "leis de seu próprio campo", e não derivá-lo de estruturas ou conteúdos internos ou externos pré-concebidos. Isto é,

além da oposição artificial entre o inato e o adquirido, trata-se portanto de descrever, no momento mesmo da experiência, que ela seja precoce ou tardia, interna ou externa, motriz ou sensorial, a emergência de uma significação indecomponível. É preciso que a linguagem ouvida ou esboçada, a aparência de um rosto ou essa de um objeto de uso sejam de uma só vez para a criança o invólucro sonoro, motriz ou visual de uma intenção significativa vinda do outro. A organização e o sentido da linguagem ouvida poderão ser inicialmente muito pobres, será a inflexão da voz, a entonação que serão compreendidos antes que o material verbal. Mas de uma só vez os fenômenos sonoros, - que eu fale ou que um outro fale, - serão inseridos na estrutura expressãoexprimido, o rosto, que eu toque o meu ou que eu veja o de um outro, na estrutura alter-ego. Em outros termos, desde que tomamos por objeto de análise a consciência iniciante, nós nos damos conta que é impossível de lhe aplicar a distinção célebre da forma a priori e do conteúdo empírico (p.185). 
Em síntese, a percepção constituirá o momento mesmo da estruturação do sentido originário. De forma análoga à estrutura fisiológica do organismo, que se organiza ou se completa na relação com o meio, a percepção representa a abertura de sentido que deve encontrar em sua própria experiência e segundo suas próprias regras uma organização de sentido que não se encontra dada em outro lugar.

Sem dúvida, esta configuração de sentido se apóia sobre estruturas que lhe servem de apoio ou preparam sua emergência. Um símio não falará, mesmo que a linguagem falada pelos homens seja constante em seu meio. E, no entanto, esta primeira estruturação deve ser completada por outra de que a própria experiência será a ocasião.

Portanto, o mundo objetivo com suas relações construídas pela ciência não representa a experiência originária de mundo, e daí o caráter aparentemente animista da percepção infantil; porque ao se dizer que a percepção infantil é animista, já se pressupõe um mundo de relações objetivas, a diferença entre mundo animado e mundo inanimado; mas essa distinção é posterior, pois, originariamente, há expressões de sentido, de caráter afetivo e emocional, a realidade é experimentada e só depois visada segundo a ordem do conhecimento objetivo.

Nesse sentido se faz a crítica dos pressupostos objetivistas da ontologia clássica presentes na ciência da percepção, uma crítica que Merleau-Ponty já encontrara no próprio Cassirer, e que mostra que o movimento da ciência objetivista leva para a análise da percepção conceitos que na verdade pertencem a uma visão tardia de mundo construída pela ciência - como, por exemplo, a noção de sensação -, através da qual a ciência pensa recompor a partir do dado mais elementar, o fenômeno perceptivo. - A Fenomenologia da Percepção dedica algumas de suas páginas especialmente à crítica da noção de sensação como dado elementar da percepção e, portanto, como elemento essencial para a sua compreensão. Particularmente, Cassirer mostrou, em Filosofia das Formas Simbólicas (1972) que não compreenderemos o mito enquanto não o tomarmos como uma forma de percepção originária, isto é, enquanto supormos, anterior a ele, uma percepção de objetos em um mundo de relações objetivas, em relação ao qual o mito aparecerá sempre como algo irracional. 


\section{A crítica à noção de representação}

Mas há outra crítica a Bergson - anterior a essa que o acusa de biologizar a cultura - que diz respeito à sua própria noção de "ação", na qual Merleau-Ponty visa à correta articulação entre consciência e corpo de que vimos tratando desde o princípio. Agora, é a crítica à noção de representação que ganha espaço. Embora a intenção de Bergson fosse a de justamente unir a consciência à ação, quando afirma, por exemplo, a unidade interior do sentido dos gestos para descrever a consciência ativa, ele também, por vezes, concebe "a ação como uma série de acontecimentos exteriores entre si", sobretudo quando afirma, com o conceito de "atenção à vida", a tomada de consciência dos movimentos nascentes em nosso corpo, movimentos desencadeados automaticamente e despidos de consciência. Bergson, aí, não teria sido feliz na tentativa de ligar a consciência à ação. Para fazê-lo, seria preciso conceber um sentido presente na ação que não fosse esse da sua representação à consciência, um movimento intencional cujo sentido the fosse imanente.

Eis os limites e as implicações da noção de consciência enquanto representação e conhecimento de si: se a consciência é isso, então todo movimento corpóreo que não é precedido por uma representação consciente, ou é compreendido como automático, como montagem pré-estabelecida na relação do corpo com o meio, ou é compreendido como dirigido por representações inconscientes.

Ou seja, ou eu modifico a idéia de consciência para dar conta de uma intencionalidade e de um sentido que não são precedidos por representações, ou fico entre as alternativas do automatismo e do pensamento inconsciente.

Ora, é o próprio Bergson, diz Merleau-Ponty (1942/1972), quem

assinalou o que havia de abstrato nas psicologias que descrevem a origem empírica da percepção como se sua função fosse de uma só vez a de contemplar e a atitude primitiva do homem uma atitude de espectador. Mas ele não seguiu até o fim essa idéia. Para fazê-lo completamente, seria preciso primeiro deixar de definir a consciência pelo conhecimento de si, introduzir a noção de uma vida da consciência que ultrapassa seu conhecimento expresso de si mesma. Mas seria preciso 
ainda alguma coisa a mais: ao invés de deixar indeterminada essa vida da consciência e de se limitar com o 'concreto em geral', - como se a consciência não pudesse ultrapassar as melodias do instinto sem se liberar de toda forma determinada, - descrever as estruturas de ação e de conhecimento nas quais ela se engaja (p.178).

São duas as exigências merleau-pontyanas, portanto. Por um lado, não biologizar a ação humana nela vendo apenas uma solução mais engenhosa das questões presentes no mundo animal; nas nossas relações com o outro, na linguagem e no trabalho, na nossa experiência do mundo, em última instância, revelam-se e desenvolvem-se os paradoxos da existência humana: não há uma única ação, aí, diz Merleau-Ponty, que não receba as primeiras indicações do movimento geral da vida de que o corpo faz parte, mas nenhuma delas representa apenas esse movimento, que, como dizia Bergson, é amortizado no homem e deixa de valer como instinto. Ao contrário, pois, de Bergson, para quem a ação humana desenvolve apenas uma solução mais inteligente para suprir a indeterminação do instinto, é nela que o humano se realiza. Ou seja, trata-se de apontar para o caráter de integração e transcendência do mundo da vida no mundo da cultura:

desse novo ponto de vista, nós nos damos conta que, se todas as ações permitem uma adaptação à vida, a palavra vida não tem o mesmo sentido na animalidade e na humanidade... Sem dúvida o vestuário, a casa, servem para nos proteger do frio, a linguagem auxilia no trabalho coletivo e na análise do 'sólido inorganizado'. Mas o ato de se vestir torna-se o ato do adorno ou ainda este do pudor e revela assim uma nova atitude em relação a si mesmo e para com o outro. Apenas os homens vêem que estão nus. Na casa que ele se constrói, o homem projeta e realiza seus valores preferidos. $\mathrm{O}$ ato da fala exprime enfim que ele deixa de aderir imediatamente ao meio, eleva-o à condição de espetáculo e dele toma posse mentalmente pelo conhecimento propriamente dito (Merleau-Ponty, 1942/1972, p.188).

Por outro lado, situar a consciência nas estruturas em que ela se desenvolve. Já a consciência perceptiva mais elementar, a encontramos situada em um campo onde configurações visuais ou sonoras se organizam, desde que queiramos abstrair suas estruturas sociais e de linguagem presentes na configuração do sentido percebido. 
Ora, quando se trata da questão da encarnação ou situação da consciência no mundo, é justamente a noção de representação que se revela insuficiente e que representa o alvo de suas críticas. Possuir e contemplar uma representação não representa toda a vida significativa da consciência. É preciso, ao contrário, dar conta de uma consciência vivida anterior a uma consciência que tem diante de si objetos de conhecimento: "como a percepção iniciante é, muito mais que uma operação cognitiva e desinteressada, um contato emocional da criança com os centros de interesse de seu meio, é sobre o exemplo do freudismo, diz Merleau-Ponty (1942/1972, p. 191) que gostaríamos de precisar as relações da dialética propriamente humana com a dialética vital".

\section{Conclusão: estruturas de comportamento}

Desde o princípio trata-se, segundo ele, de recusar a interpretação causal de Freud sobre os mecanismos psicológicos de que fala a psicanálise: a formação dos complexos, a repressão, a regressão, a transferência, são fatos que podem ser descritos em outra linguagem que não a das relações causais e inconscientes. Aqui, é Politzer a principal referência de Merleau-Ponty, mas ele assume a teoria politzeriana na perspectiva da idéia de estrutura que vimos tratando. Em primeiro lugar, trata-se de enfatizar que a consciência pode viver com sentido mais do que aquilo que ela se representa. Em segundo lugar, de assumir a aparente independência de forças desorganizadoras da conduta no neurótico, a partir da teoria do desenvolvimento da libido, ou do desenvolvimento do eu nas relações com o outro. Aí, podemos notar, segundo Merleau-Ponty, que o desenvolvimento da libido é o de uma estruturação progressiva e descontínua do comportamento. No caso, "a estruturação normal é esta que reorganiza a conduta em profundidade, de tal maneira que as atitudes infantis não tenham mais lugar nem sentido na atitude nova; ela levaria a um comportamento perfeitamente integrado do qual cada momento estaria ligado ao conjunto" (Merleau-Ponty, 1942/1972, p.192). Do contrário,

diremos que há recalque quando a integração só foi realizada em aparência e deixa subsistir no comportamento certos sistemas relativa- 
mente isolados que o sujeito recusa ao mesmo tempo de transformar e de assumir. Um complexo é um segmento de conduta desse gênero, uma atitude estereotipada, uma estrutura de consciência adquirida e durável em relação a uma categoria de estímulo. Uma situação que, por ocasião de uma experiência inicial, não pudera ser dominada e dera lugar à angústia e à desorganização que acompanham o fracasso, não é mais experimentada diretamente: o sujeito apenas a percebe através da fisionomia que ela tomou no momento da experiência traumática (p. 192).

Nessas condições, cada experiência seguinte que se relaciona a essa categoria de estímulo cuja integração na experiência foi bloqueada, na verdade não pode ser uma experiência nova, porque apenas repete o resultado da precedente. Podemos dizer, como Merleau-Ponty na "Fenomenologia da Percepção", que o tempo, então, fechou-se para o sujeito, e que o presente se transformou na repetição do passado, nesse setor da experiência em que o acontecimento traumático deveria ser ou abandonado ou integrado às condutas do indivíduo e não foi, uma vez que o sujeito tanto foi incapaz de abandonar as vias em que se engajava, como de assumi-las em sua existência. A aparente autonomia ou força dos complexos na sua vida nada mais seria, portanto, do que a permanência de condutas não integradas à sua vida atual, e que ele se recusa a assumir. Em síntese, "o que é exigido pelos fatos que Freud descreve sob o nome de recalque, de complexo, de regressão ou de resistência, é apenas a possibilidade de uma vida de consciência fragmentada que não possui em todos os seus momentos uma significação única" (Merleau-Ponty, 1942/1972, p.193).

É essa idéia de uma estruturação progressiva dos atos de conduta que permite distinguir o comportamento patológico do movimento efetivo da existência humana. A obra de Freud seria, nesse sentido, não um quadro geral sobre a existência humana, mas um quadro de anomalias

na medida em que a sublimação só é uma derivação de forças biológicas não empregadas, a atividade nova deve conservar o modo irregular, a labilidade característica das condutas não integradas; nos casos onde a sublimação e a transferência tiveram, ao contrário, êxito, é que as energias vitais não são mais as forças motrizes do comportamento, 
que elas foram realmente integradas a um conjunto novo e suprimidas como forças biológicas (Merleau-Ponty, 1942/1972, p.194).

\section{Em termos gerais,}

o comportamento superior guarda na profundidade presente de sua existência as dialéticas subordinadas, desde aquela do sistema físico e de suas condições topográficas até aquela do organismo e de seu 'meio'. Elas não são reconhecíveis no conjunto, quando ele funciona corretamente, mas sua iminência é atestada pela desintegração em caso de lesão parcial (Merleau-Ponty, 1942/1972, p. 224).

Nisso se apóia Pontalis (1961), ao apontar que a noção de inconsciente n'“A Estrutura do Comportamento" representa um nível inferior de organização da conduta. Diz ele:

(S)em dúvida esta distinção não deve ser tomada em um sentido substancial, mas puramente funcional. Todavia, as imagens, tradicionais em psicologia, de hierarquia e de nível - que conduzem a assimilar o inconsciente ao inferior - continuam a operar. Testemunham estas linhas: 'A regressão do sonho, a eficácia de um complexo adquirido no passado, enfim, o inconsciente do recalcado apenas manifestam o retorno de uma maneira primitiva de organizar a conduta, um arqueamento das estruturas mais complexas e um recuo na direção das mais fáceis' (p. 288).

Não há, de fato, como negar o caráter integracionista presente nessa idéia de progressivas estruturações da conduta, uma idéia que, como aponta Pontalis, aproxima Merleau-Ponty da perspectiva de Goldstein. É preciso, no entanto, nuançar essa posição. A integração das ordens inferiores nas superiores, do comportamento vital no comportamento humano, ou de atitudes mais simples nas mais complexas, nunca é completa. Como diz o próprio Merleau-Ponty (1942/1972) na parte final de seu texto, junto da integração da ordem inferior na superior, há uma dualidade que aparece sempre em um nível ou outro; junto à "alma", ainda é preciso reconhecer que "o corpo em geral é um conjunto de caminhos já traçados, de poderes já constituídos” (p. 227).

A "Fenomenologia da Percepção" virá para nuançar mais esse caráter integracionista ou, poderíamos também dizer, esse caráter 
unificador do sentido da existência, ao enfatizar tanto a ambigüidade de sentido de todos os nossos atos, como também o fato deles possuírem sempre mais de um sentido.

\section{Referências}

Cassirer, E. (1972). La Philosophie des Formes Symboliques, 3. La phénoménologie de la connaissance. Paris: Minuit.

Merleau-Ponty, M. (1972). La Structure du Comportement. Paris: Gallimard. (Originalmente publicado em 1942).

Merleau-Ponty, M. (1994). Fenomenologia da Percepção. São Paulo: Martins Fontes (Originalmente publicado em 1945).

Merleau-Ponty, M. (1968). Résumés de Cours - Collège de France-1952-1960. Paris: Gallimard.

Pontalis, J. B. (1961). Note sur le problème d'inconscient chez Merleau-Ponty. Les Temps Modernes - Maurice Merleau-Ponty, numéro spécial, 287-303.

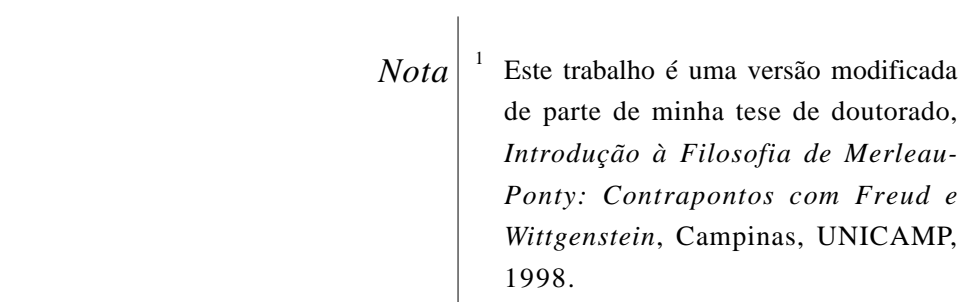

Reinaldo Furlan, doutor em FiloSobre o autor sofia pela Universidade Estadual de Campinas (SP) e mestre em Filosofia e Metodologia das Ciências pela 
400 R.Furlan

Universidade Federal de São Carlos (SP), é professsor do Departamento de Psicologia e Educação da Faculdade de Filosofia, Ciências e Letras de Ribeirão Preto, Universidade de São Paulo, SP. Endereço para correspondência: Av. Bandeirantes, 3900, 14040901, Ribeirão Preto, SP. E-mail: reinaldof@ffclrp.usp.br.

Recebido em 24.07.00 